\title{
Natural History of Paclitaxel-associated Acute Pain Syndrome: A Case Report of Rare Side Effect of Paclitaxel
}

\author{
Siti Salima D, Ali Budi Harsono (D), Aisyah Aisyah (D), Kemala Mantilidewi* (D) \\ Department of Obstetrics and Gynecology, Faculty of Medicine, Universitas Padjadjaran, Dr. Hasan Sadikin Hospital, Bandung, \\ West Java, Indonesia
}

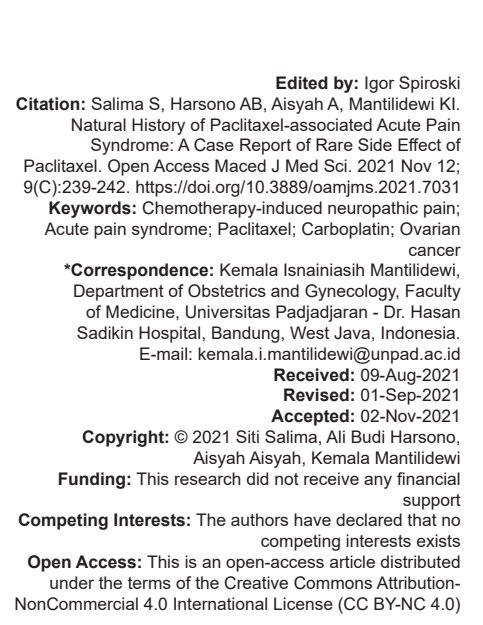

\section{Abstract}

BACKGROUND: One of the harshest side effects following anticancer agent treatments is chemotherapy-induced neuropathic pain. After surgical staging, chemotherapy combination of paclitaxel carboplatin could be a choice of therapy for Stage II or more advanced stage of ovarian cancer. Different side effects may appear after the application of paclitaxel.

CASE REPORT: Here, we show an uncommon case of paclitaxel-acute pain syndrome (P-APS), and how we deal with such cases according to our experiences. One uncommon side effect is P-APS, which can be treated effectively with the administration of non-steroidal anti-inflammatory drugs, corticosteroid, and supportive therapy.

CONCLUSION: One uncommon side effect of Paclitaxel induced neuropathic can be treated effectively with the administration of non-steroidal anti inflammatory drugs, corticosteroid, and supportive therapy.

\section{Introduction}

Ovarian cancer is one of the lethal gynecological cancers after cervical cancer. The American Cancer Society estimates in 2021 there will be 21,410 new ovarian cancer cases causing 13,770 deaths in the United States [1]. The National Cancer Institute states that the rate of new ovarian cancer cases is $11.2 / 100,000$ with a death rate of $6.7 / 100,000$ women per year [2]. Ovarian cancer is often referred to as the silent killer because of the nature of the cancer is asymptomatic thus causing delayed onset of symptoms, and until now there is lack of proper screening method [3], [4]. These cause patients would come in the advanced stage.

The management of advanced ovarian cancer includes surgery combines with chemotherapy with platinum compounds and taxanes, although carrying various side effects [5], [6], [7], [8]. Paclitaxel is a chemotherapy drug frequently used in the breast, ovarian, lung, and head and neck cancers that have side effects of acute and sub-acute pain called paclitaxel associated acute pain syndrome
(P-APS) [9], [10], [11], [12]. The presence of acute pain in patients is often associated with chemotherapyinduced peripheral neuropathy (CIPN).

CIPN is a widely known harmful effect of anticancer drugs [13]. Neuropathic pain symptoms are reported to exist in nearly $19-85 \%$ of the cancer patients after they received the administration of anticancer drugs such as platinum compounds, proteasomes inhibitors, and antitubulins (e.g. vinca alkaloids and taxanes) [14], [15]. The frontline chemotherapeutic agent, paclitaxel, is used to treat a number of solid tumors, but the presence of a high incidence of CIPN severely devastates the patient's quality of life, which leads to dose reduction or even treatment discontinuation [16].

Painful symptoms, the characteristic of a neuropathic pain syndrome, are usually the manifestation of peripheral neuropathy, which can develop to dysfunction of sensory perception in the most severe cases. Furthermore, motor and/or autonomic peripheral neuropathy may also take place [8], [13].

However, there have not been working agents or clinical protocols to effectively stop and reverse CIPN. Although the mechanisms of CIPN are not known 
entirely, growing evidence confirms that paclitaxel administration improves sensitivity to mechanical and cold stimuli (mechanical and cold allodynia) targeting peripheral sensory neurons in the dorsal root ganglia (DRGs), which leads to oxidative stress and neuroinflammation, resulting in degeneration of intraepidermal nerve fiber density [17], [18]. Here, we share natural history of the application of paclitaxel chemotherapy to a patient along with successful management for removing the P-APS.

\section{Case Presentation}

The case is about a 35-year old female in Bandung City, West Java, Indonesia, diagnosed with stage IIIA1 ovarian cancer. She received complete surgical staging with histopathology result of muscinous cystadenocarcinoma of left ovary and the presence of pelvic lymph node metastasis.

The following post-operative management was chemotherapy paclitaxel with a dosage of $175 \mathrm{mg} / \mathrm{m}^{2} \mathrm{IV}$ for $6 \mathrm{~h}$ in every 3 weeks for 6 courses, administered together with carboplatin with dosage of area under the curve (AUC) 5. Upon starting her first course of chemotherapy, the patient complained about shooting pain at her left gluteus spreading to the left sole in particular at her toe after $12 \mathrm{~h}$ of the treatment, with the numerical rating scale (NRS) showing at scale 9-10. In the beginning, she was treated with nonsteroidal antiinflammatory drug orally as outpatient. The pain did not go away for 3 days with reduction of pain at the scale only to 6-7, and then it disappeared within 1 week.

After the observation on the temporal characteristic of the pain, the paclitaxel carboplatin chemotherapy was administered for her second course. During this course, the pain relapsed earlier which was $10 \mathrm{~h}$ after the application of chemotherapy. Pain scale was 9 by NRS, but this time the patient

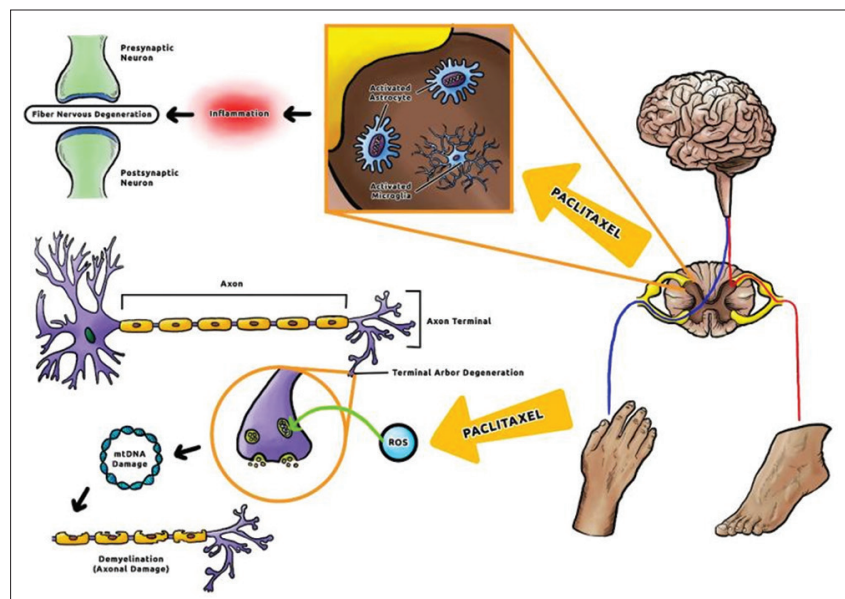

Figure 1: Suggested pathophysiology of paclitaxel-induced neuronal injury was hospitalized for pain treatment and supplemented with nonsteroidal anti-inflammatory drug orally, methylcobalamin $1500 \mathrm{mcg} /$ day orally along with prednisone $5 \mathrm{mg}$ twice a day orally. The pain became less intensive to 5 , and after 7 days of her being hospitalized, the pain disappeared.

As we identified the pain relapsing in the second course of paclitaxel carboplatin chemotherapy, the conclusion was that the patient had suffered from P-APS. Consequently in the third course of chemotherapy paclitaxel was replaced with Gemcitabine $750 \mathrm{mg} / \mathrm{m}^{2}$ IV on day 1 and day 8 parallel with carboplatin AUC 5 on day 1, repeated in 21-day cycles. There was a significant pain reduction to scale 2 by NRS. The patient agreed to continue taking the nonsteroidal anti-inflammatory drug orally when needed.

\section{Discussion}

In this case, the patient felt severe pain $12 \mathrm{~h}$ after the administration of paclitaxel. In contrast to Reeves's et al. study, the pain associated with paclitaxel administration would increase on day 4 after paclitaxel administration [11]. Reeves's study showed the most common type of pain was itching while shooting pain has a low percentage of pain types, around $18 \%$. In current case, pain was felt in the hips and lower extremities; this is in line with another cohort study by Reeves [12].

CIPN is experienced by as many as $19-85 \%$ of patients administered with chemotherapeutic drugs, like paclitaxel [14], [15]. Nevertheless, CIPN is still inevitable as there is no clinical treatment that might prevent or reverse CIPN yet [14], [15]. At the current study, we are studying a case of paclitaxel-induced neuropathy and our findings in treating such a case.

Some physiopathological mechanisms have already been identified for CINP comprising alterations in axonal transport, mitochondrial damage, increasing ion channel activity and inflammation in the central nervous system (CNS) [11], [12]. We suggested the mechanisms involved in P-APS/CIPN may require several pathways, as manifested in Figure 1.

Paclitaxel is one the foremost efficacious chemotherapeutic drugs, yet it is attributed to the development of CIPN symptoms comprising among others persistent shooting, stabbing, or burning pain, and most often loss of sensation of "numbness" [11], [12]. Although mice given with the chemotherapeutic agent cisplatin demonstrated noteworthy sensory motor deficit using the well characterized adhesive removal test as an indication of numbness, the same deficits were not seen in 
those administered with paclitaxel not seen in mice administered with paclitaxel [12]. However, it is well documented that paclitaxel-treated animals have improved sensitivity to mechanical stimuli (mechanical allodynia), and this particular increased sensitivity is widely applied as a readout for the development of CIPN [19].

There is no single theory that can explain the difference between P-APS and CIPN since then. However, several studies conducted by Reeves can support that P-APS and CIPN are different clinical groups but manifest neurological disorders [11]. In clinical trials using mice, there was damage to DRG $24 \mathrm{~h}$ after administration of paclitaxel, and this supports the theory that P-APS is a manifestation of neurological toxicity [20].

Degeneration of peripheral nerves can occur due to malfunctioning of the mitochondria and microtubules which will affect axonal transport caused by chemotherapy drugs [21]. Platinum agents caused damage to DRG with apoptotic activation by changing the Schwan and satellite cells [22], [23].

Furthermore, chemotherapy drugs cause damage to mitochondrial DNA and electron transport chain proteins and trigger reactive oxygen species (ROS) as known as oxidative stress [24]. The stress factor strongly influences the production of ROC in cells. ROS caused phospholipids' damage, resulting in demyelination, oxidized proteins, and an increase in carbonyl by-products, which can activate transient receptor potential vanilloid (TRPV) channels [24].

TRPV receptors are found mainly in the peripheral nervous system's nociceptive neurons, including the CNS. The activated TRP channels allowing ions such as sodium to flow into the cell. TRPV is involved in the transmission and modulation of pain and causing diverse painful stimulation [25].

The overexcitation of peripheral nociceptors of which the intracellular ROS stimulates, caused the increase of pro-inflammatory mediators such as (interleukin [IL]-1 $\beta$, tumor necrosis factor- $\alpha$, bradykinin, and nerve growth factors) [26]. These functional disorders lead to peripheral neuropathic injuries in the neurons and cause complaints ranging from mildto-severe rate pain in patients with cancer-induced chemotherapy. Therefore it is necessary to prevent and manage CIPN in patients. However, there are no specific interventions recommended in the management and prevention of CIPN.

Administration of prednisone in humans has been reported to reduce P-APS [27]. Furthermore, randomized control trials using mice reported that minocycline (a selective microglia/macrophage inhibitor and anti-inflammatory cytokine IL-10) could reduce mechanical allodynia [28]. Damage to the DMG was associated with pain in the P-APS responsible for CIPN. Dexamethasone administration has also been reported to be safe and beneficial in reducing the severity of P-APS [29].

\section{Conclusion}

One uncommon side effect of Paclitaxel induced neuropathic can be treated effectively with the administration of non-steroidal anti inflammatory drugs, corticosteroid, and supportive therapy.

\section{Authors' Contributions}

All authors contributed equally.

\section{References}

1. Society AC. Key Statistics for Ovarian Cancer Atlanta: Leo and Gloria Rosen Family; 2021. Available from: https://www.cancer. org/cancer/ovarian-cancer/about/key-statistics.html [Last accessed on 2021 Feb 25].

2. Institute NC. Surveillance, Epidemiology, and End Results Program. Cancer Stat Facts: Ovarian Cancer; 2021. Available from: https://seer.cancer.gov/statfacts/html/ovary.html [Last accessed on 2021Feb 25].

3. Jayson GC, Kohn EC, Kitchener HC, Ledermann JA Ovarian cancer. Lancet. 2014;384(9951):1376-88. https://doi. org/10.1016/s0140-6736(13)62146-7

PMıd:24767708

4. Slatnik CL, Duff E. Ovarian cancer: Ensuring early diagnosis. Nurse Pract. 2015;40(9):47-54. https://doi.org/10.1097/01. npr.0000450742.00077.a2 PMıd:26274886

5. Querleu D, Planchamp F, Chiva L, Fotopoulou C, Barton D, Cibula D, et al. European society of gynaecological oncology (ESGO) guidelines for ovarian cancer surgery. Int J Gynecol Cancer. 2017;27(7):1534-42. https://doi.org/10.1097/ igc.0000000000001041

PMıd:30814245

6. Armstrong DK, Alvarez RD, Bakkum-Gamez JN, Barroilhet L, Behbakht K, Berchuck A, et al. NCCN guidelines Insights: Ovarian cancer, version 1.2019: Featured updates to the NCCN guidelines. J Natl Comp Cancer Network. 2019;17(8):896-909. https://doi.org/10.6004/jnccn.2019.0039 PMıd:31390583

7. Gornstein EL, Schwarz TL. Neurotoxic mechanisms of paclitaxe are local to the distal axon and independent of transport defects. Exp Neurol. 2017;288:153-66. https://doi.org/10.1016/j. expneurol.2016.11.015

PMıd:27894788

8. Da Costa R, Passos GF, Quintão NL, Fernandes ES, Maia JR, Campos MM, et al. Taxane-induced neurotoxicity: Pathophysiology and therapeutic perspectives. Br J Pharmacol. 
2020;177(14):3127-46. https://doi.org/10.1111/bph.15086 PMıd:32352155

9. Rowinsky E, Eisenhauer E, Chaudhry V, Arbuck S, Donehower RC, editors. Clinical Toxicities Encountered with Paclitaxel (Taxol). Seminars in Oncology; 1993.

10. Garrison JA, McCune JS, Livingston RB, Linden HM, Gralow JR, Ellis GK, et al. Myalgias and arthralgias associated with paclitaxel. Oncology (Williston Park, NY). 2003;17(2):271-7; discussion 81.

PMıd:12632867

11. Reeves BN, Dakhil SR, Sloan JA, Wolf SL, Burger KN, Kamal A, et al. Further data supporting that paclitaxel-associated acute pain syndrome is associated with development of peripheral neuropathy: North Central Cancer Treatment Group trial N08C1. Cancer. 2012;118(20):5171-8. https://doi.org/10.1002/ cncr.27489

PMıd:22415454

12. Loprinzi CL, Reeves BN, Dakhil SR, Sloan JA, Wolf SL, Burger KN, et al. Natural history of paclitaxel-associated acute pain syndrome: prospective cohort study NCCTG N08C1. J Clin Oncol. 2011;29(11):1472-8. https://doi.org/10.1200/ jco.2010.33.0308

PMıd:21383290

13. Quintão NL, Santin JR, Stoeberl LC, Corrêa TP, Melato J, Costa R. Pharmacological treatment of chemotherapyInduced neuropathic pain: PPAR $\gamma$ agonists as a promising tool. Front Neurosci. 2019;13:907. https://doi.org/10.3389/ fnins. 2019.00907

PMıd:31555078

14. Zajączkowska R, Kocot-Keppska M, Leppert W, Wrzosek A, Mika J, Wordliczek J. Mechanisms of chemotherapy-ınduced peripheral neuropathy. Int J Mol Sci. 2019;20(6):1451. https:// doi.org/10.3390/ijms20061451 PMıd:30909387

15. Fallon MT. Neuropathic pain in cancer. $\mathrm{Br} \mathrm{J}$ Anaesth. 2013;111(1):105-11. PMıd:23794652

16. Miltenburg N, Boogerd W. Chemotherapy-induced neuropathy: A comprehensive survey. Cancer Treatment Rev. 2014;40(7):872-82. https://doi.org/10.1016/j.ctrv.2014.04.004 PMıd:24830939

17. Licht T, Keilani M, Crevenna R. Chemotherapy-induced peripheral neuropathy (CIPN). Memo 2021;14:1-5. https://doi. org/10.1007/s12254-021-00688-3

18. Colvin LA. Chemotherapy-induced peripheral neuropathy (CIPN): Where are we now? Pain 2019;160(Suppl 1):S1-10. https://doi.org/10.1097/j.pain.0000000000001540 PMıd:31008843

19. Xu J, Zhang L, Xie M, Li Y, Huang P, Saunders TL, et al. Role of complement in a rat model of paclitaxel-induced peripheral neuropathy. J Immunol. 2018;200(12):4094-101. https://doi. org/10.4049/jimmunol.1701716

PMıd:29695418
20. Jimenez-Andrade JM, Peters CM, Mejia NA, Ghilardi JR, Kuskowski MA, Mantyh PW. Sensory neurons and their supporting cells located in the trigeminal, thoracic and lumbar ganglia differentially express markers of injury following intravenous administration of paclitaxel in the rat. Neurosci Lett. 2006;405(1-2):62-7. https://doi.org/10.1016/j. neulet.2006.06.043

PMıd:16854522

21. Jordan MA, Wilson L. Microtubules as a target for anticancer drugs. Nat Rev Cancer. 2004;4(4):253-65.

PMıd:15057285

22. Grisold W, Cavaletti G, Windebank AJ. Periphera neuropathies from chemotherapeutics and targeted agents: Diagnosis, treatment, and prevention. Neurooncology. 2012;14(Suppl 4):iv45-54. https://doi.org/10.1093/neuonc/ nos203

PMıd:23095830

23. Han Y, Smith MT. Pathobiology of cancer chemotherapy-induced peripheral neuropathy (CIPN). Frontiers in pharmacology. 2013;4:156. https://doi.org/10.3389/fphar.2013.00156

\section{PMıd:24385965}

24. Salvemini D, Little JW, Doyle T, Neumann WL. Roles of reactive oxygen and nitrogen species in pain. Free Radical Biology and Medicine. 2011;51(5):951-66. https://doi.org/10.1016/j. freeradbiomed.2011.01.026

PMıd:21277369

25. Moran MM, Xu H, Clapham DE. TRP ion channels in the nervous system. Curr Opin Neurobiol. 2004;14(3):362-9. https:// doi.org/10.1016/j.conb.2004.05.003

PMıd:15194117

26. Wang T, Qin L, Liu B, Liu Y, Wilson B, Eling TE, et al. Role of reactive oxygen species in LPS-induced production of prostaglandinE2 in microglia. J Neurochem. 2004;88(4):939-47. https://doi.org/10.1046/j.1471-4159.2003.02242.x

PMıd:14756815

27. Markman M, Kennedy A, Webster K, Kulp B, Peterson G Belinson J. Use of low-dose oral prednisone to prevent paclitaxel-induced arthralgias and myalgias. Gynecol Oncol. 1999;72(1):100-1. https://doi.org/10.1006/gyno.1998.5226 PMıd:9889038

28. Liu CC, Lu N, Cui Y, Yang T, Zhao ZQ, Xin WJ, et al. Prevention of paclitaxel-induced allodynia by minocycline: Effect on loss of peripheral nerve fibers and infiltration of macrophages in rats. Mol Pain. 2010;6:76. https://doi.org/10.1186/1744-8069-6-76 PMıd:21050491

29. Saito Y, Kobayashi M, Yamada T, Sakakibara-Konishi J, Shinagawa N, Kinoshita I, et al. Efficacy of additional dexamethasone administration for the attenuation of paclitaxel-associated acute pain syndrome. Support Care Cancer. 2020;28(1):221-7. https://doi.org/10.1007/ s00520-019-04808-y

PMıd:31016422 